\title{
Personal resources and flexibility in coping with stress depending on perceived stress in a group of cancer patients
}

\begin{abstract}
BACKGROUND
Cancer is a highly stressful life event. It requires the employment of new coping skills and strategies. Flexibility in coping with stress plays an important role in this case. The aim of the study was to assess the role of personal resources in shaping the flexibility in coping with stress among cancer patients depending on the level of perceived stress.

PARTICIPANTS AND PROCEDURE

One hundred eight patients suffering from cancer were surveyed. The following methods were employed: the Resiliency Measurement Scale by Ogińska-Bulik and Juczyński, the Adult Hope Scale by Snyder, the Spirituality Index of Well-Being by Daaleman and Frey, the Flexibility in Coping with Stress Questionnaire by Basińska and team and the Global Measure of Perceived Stress by Cohen, Kamarck and Mermelstein.
\end{abstract}

\section{RESULTS}

The results demonstrated a positive correlation between all considered personal resources and flexibility in coping.

\begin{abstract}
Both resiliency and spiritual well-being enable one to predict $23 \%$ of variability of flexibility in coping. Cluster analysis revealed that the group of patients with a generally higher level of personal resources was characterised by greater flexibility in all its dimensions. However, stress levels did not modify the relationships between personal resources and flexibility in coping.
\end{abstract}

\section{CONCLUSIONS}

The results encourage the planning of psychological interventions aimed at the development of personal resources among cancer patients, and warrant further research.

\section{KEY WORDS}

hope; resiliency; spirituality; cancer patients; flexibility in coping with stress 


\section{BACKGROUND}

Cancer is an example of a crisis situation which affects both the patient and the patient's close relatives. Therefore, its diagnosis is a highly stressful event, which can take a different course in each patient. Moreover, every stage of the disease - suspicion, diagnostic tests, confirmation of the disease, treatment, hospitalisation, post-treatment period - is accompanied by a high level of psychological stress. For this reason, the occurrence of an oncological disease requires the employment of new coping strategies. Patients cope with the disease in a variety of ways, but only a few of them manage to maintain a mental balance. The majority of patients show signs of distress (Juczyński, 2002). Many of them also experience physical symptoms caused by the disease and its treatment, and face fear and anxiety due to the further effects of the disease or the possibility of death. The strategies the patients employ to cope with the disease are important for adapting to this situation (Spendelow, Eli Joubert, Lee, \& Fairhurst, 2018), and influence the health-related quality of life, including in particular the mental condition and mood (Cheng et al., 2012; Nipp et al., 2017), and thus the effect on the immune system, which influences the healing process (cf. Ashraf et al., 2018; D'Acquisto, 2017).

The transactional model of stress and coping by Lazarus and Folkman (1984) highlights the importance of appraising stress, as well as the ability to cope with it for adjustment to disease (Curtis, Groarke, McSharry, \& Kerin, 2014; Kato, 2015). According to Lazarus and Folkman (1984), the individual's way of thinking, feelings, and actions result from the interaction between the objective properties of a situation and the person's traits. In stressful situations, the event is confronted with the values, beliefs and skills of the individual. This confrontation result is the interpretation of the situation, which serves as the basis for the emotions experienced by the individual. The cognitive appraisal of the event is based on cognitive activity and the related emotionality. Lazarus and Folkman (1984) distinguished three types of it: primary appraisal, secondary appraisal and reappraisal. Primary appraisal is a process in which a person evaluates the relevance of a particular situation to his or her well-being. It may be irrelevant, benignpositive or stressful, and further interpreted as harm/ loss, threat and challenge. As proposed by Lazarus (1986), psychological stress relates to the requirements faced by an individual which, in his or her opinion, exhaust or exceed the internal and external resources available to him or her. Primary appraisal determines the intensity and type of the emotional response to any event.

According to the transactional stress theory, secondary appraisal is an important element of the ad- aptation process. During secondary appraisal, a decision is made, either consciously and deliberately, or unconsciously and automatically, about how to act in a specific circumstance and how to cope with it (Lazarus, 1986).

The third type of cognitive appraisal in stressful situations (reappraisal, which follows secondary appraisal) is often disregarded in studies about stress and stress coping. It relates to appraisal based on information from the environment, as well as on an individual's own response after applying a coping strategy. Should the strategy chosen at the secondary appraisal stage fail, then, at the reappraisal stage, the individual can adjust the coping strategy and choose another way of addressing the stressful situation. If the coping strategy was appropriate and effective, the transaction is no longer viewed as stressful during the reappraisal. An important feature of reappraisal is the ability of an individual to replace previous, ineffective coping strategies with other strategies in order to succeed in coping with stress (Lazarus \& Folkman, 1984).

\section{FLEXIBILITY IN COPING AND ITS IMPORTANCE IN FUNCTIONING DURING ILLNESS}

The concept of flexibility in coping broadens the understanding of coping. The assessment of the coping strategies and styles employed is embedded in the context of the effectiveness of the applied coping strategies. Flexibility in coping can be understood in terms of its various aspects: (1) as a repertoire of coping strategies available to the individual, (2) as inter-situational changeability, which relates to one's ability to use various strategies depending on specific conditions; (3) as an ability to choose the appropriate coping strategy depending on its effectiveness so far, thus facilitating adaptation (Kato, 2015; Basińska et al., in print).

Being diagnosed with cancer is a special situation, which is very difficult and stressful. Dealing with this situation requires a great effort in finding ways to cope with it. It appears that in this case it is of particular importance to have a broad repertoire of coping strategies, and to be able to easily decide to abandon ineffective strategies in favour of seeking more effective alternatives (Basińska et al., 2017).

The coping strategies usage type influences the overall functioning of the patient in different areas. The ability to remain flexible may be a particularly important skill when it comes to overcoming challenges posed by the disease (Spendelow et al., 2018), especially given that people who display greater coping flexibility are more likely to focus on the task and more likely to choose active coping strategies (Stępka-Tykwińska, 2015). Research results indicated that people who are flexible in coping with difficult 
situations are less depressed (Kato, 2001), go through mourning less shaken (Burton et al., 2012) and have better mental health (Saito \& Kamimura, 2011). The results of the existing research confirmed that cancer patients who are able to react flexibly to a situation are characterised by a higher quality of life (Cheng et al., 2012). Flexibility also helps them to cope with difficulties associated with the disease, its treatment and side-effects (Reese, Keefe, Somers, \& Abernethy, 2010), thus protecting these individuals from other disorders (Kirsh, McGrew, \& Passik, 2004).

Cheng's study (2012) demonstrated that patients with gastrointestinal cancer who are flexible and active were more aware of their ability to control various aspects of treatment and report improved wellbeing.

To recapitulate, coping with stress means employing a variety of strategies to remove threats. Having at one's disposal a multitude of coping strategies increases the probability of achieving this objective. When coping with cancer diagnosis and treatment, patients can draw on a wide range of internal and external resources, which can contribute directly and indirectly to improvement of their health (Hobfoll, 1998).

\section{THE ROLE OF PSYCHOLOGICAL RESOURCES: RESILIENCY, HOPE AND SPIRITUALITY IN THE FUNCTIONING OF THE INDIVIDUAL}

According to Hobfoll (1998), everything that is of value to people can be a resource. These include not only objects, but also certain conditions, personal and energy resources which may be directly or indirectly necessary for the survival of the individual, or which may be used to obtain other specific resources contributing to that individual's survival.

Personal and social resources facilitate adjustment to critical life events and increase the efficacy of coping with stressful circumstances. In addition, they play an important role in dealing with trauma and thus enable adjustment to new situations (Ogińska-Bulik \& Juczyński, 2008). They help cancer patients in reduction of distress (Gilbar, 2003) and were predictors of a longer life (Surtees, Wainwright, Luben, Khaw, \& Day, 2006). Personal resources may also favour post-traumatic growth, leading to positive changes in, e.g., self-perception, interpersonal relations and the philosophy of life (Ogińska-Bulik, 2015). Patients receiving chemotherapy who were characterised by greater optimism and self-efficacy experienced fewer mood disturbances, were less avoidant, and appraised their disease more positively (Sumpio, Jeon, Northouse, \& Knobf, 2017). Spanish research has explicitly demonstrated that hope, optimism, social support, being male and older were associated with a significantly lower risk of anxiety and depression in cancer patients (Jimenez-Fonseca et al., 2018). Moreover, cancer patients recovered more quickly from surgery when they perceived themselves as having higher self-efficacy and received more social support (Schulz \& Mohamed, 1982). In a group of women with breast cancer, selfefficacy for coping with the disease was a moderator between stress and the quality of life (Chirico et al., 2017). Women after mastectomy were characterized by a lower level of one resiliency level - perseverance and determination in action, which indicates their ability to cope (Izydorczyk, Kwapniewska, Lizińczyk, \& Sitnik-Warchulska, 2019).

In this group of patients, various aspects of religious life were also used as resources. These included positive religious coping or the degree of organisation of religiousness. Reducing negative religious coping contributed to lower psychological distress in the group of cancer patients $(\mathrm{Ng}$, Mohamed, Sulaiman, \& Zainal, 2017). Religiosity and/or spirituality played a particularly significant role for people for whom faith constituted a relevant aspect of their lives. It is, therefore, important that the treatment personnel are able to identify such individuals and support their beliefs, in order to provide them with comprehensive care (Nejat, Whitehead, \& Crowe, 2017). Extensive studies involving cancer patients demonstrated that intrinsic religiousness and control-related religious coping were correlated to the various dimensions of their well-being (Pérez \& Rex Smith, 2015).

Existing research has not provided much insight into the relationship between flexible coping and personal resources. People who were more resilient and hopeful proved to be more flexible in coping with stress (Basińska et al., 2017; Borzyszkowska \& Basińska, 2018; Góralska \& Basińska, 2019). Studies involving people with chronic diseases confirmed that those with a higher sense of coherence and stronger spirituality were more flexible (Basińska, 2015).

In conclusion, it should be stressed that the transactional model of stress and coping highlights the role of stress appraisal in adjustment to illness. The cognitive appraisal of events and personal resources are important in adjusting to a situation involving an oncological disease (Curtis et al., 2014).

\section{THE AIM OF THE STUDY AND RESEARCH PROBLEMS}

The study aim was to determine the specific relationship between resiliency, hope and spiritual wellbeing and flexibility in coping in a group of cancer patients, as well as to verify whether the stress they perceive acts as a moderator of these relationships. Based on the presented theoretical background and
Personal resources and flexibility in coping in a group of cancer patients 
previous research results, the following research hypotheses were formulated:

H1. Personal resources - resiliency, hope and spiritual well-being - positively correlate with flexibility in coping with stress and its dimensions (repertoire, changeability, reflexivity) in cancer patients.

H2. The model of patients' personal resources (obtained in the cluster analysis) differentiates their coping flexibility.

H3. The sense of stress is a moderator of relation-
Małgorzata

A. Basińska, Michalina Sołtys ship between personal resources and flexibility in coping with stress in cancer patients.

\section{PARTICIPANTS AND PROCEDURE}

\section{PARTICIPANTS}

The study involving 108 hospitalised cancer patients (45 males and 63 females) was conducted in 2017. The study was carried out individually, with respect for ethical principles, following approval from the Bioethics Committee (UMK CM - KB 40/2017). The inclusion criteria were the medical diagnosis of a cancer disease and the age of majority. The exclusion criterion was age over 70 . The duration of treatment ranged from 1 month to 21 years. In the studied sample, 28 (25\%) patients had a relapse. The examined group was heterogeneous in terms of diagnosis. Most patients suffered from gastrointestinal $(n=31)$, breast $(n=31)$, reproductive $(n=14)$ and diffuse $(n=11)$ neoplasms. In $64(59 \%)$ subjects, a family history of oncological diseases was established. Fifty patients (46\%) also suffered from another chronic disease.

In terms of socio-demographic characteristics, the vast majority of subjects were married $(n=86,80 \%)$. Eight people $(7 \%)$ were widowed, five were divorced $(4.5 \%)$ or were in informal relationships $(4.5 \%)$. Four persons were single $(4 \%)$. The majority of patients $(n=38,35 \%)$ had secondary education. A similar number of patients had vocational education $(n=30$, $28 \%)$ and higher education $(n=29,27 \%)$. The least represented group comprised people with primary education $(n=11,10 \%)$. The age of the patients ranged from 23 to $70(M=56.00, S D=10.00)$.

\section{STATISTICAL ANALYSES}

Statistical analyses were performed using the STATISTICA 12 and SPSS Statistics 25 statistical programs. Also, descriptive statistics and measures of asymmetry and concentration of distribution (skewness and kurtosis) were used to characterise the surveyed group and select appropriate statistical tests. In order to verify the research hypotheses, Pearson and Spearman correlations, multiple linear regression analysis and hierarchical linear regression analysis were applied. Models with a moderator were tested using the PROCESS macro implemented in SPSS Statistics 25 by the bootstrapping method, drawing 5,000 samples (Hayes, 2012). Furthermore, agglomeration cluster analysis (complete-linkage method, taking Euclidean distances as a measure), $\mathrm{k}$-means clusters analysis and different significance tests were used.

\section{OPERATIONALISATION OF VARIABLES}

Two groups of variables occur in the analysed model. The response variable is flexibility in coping, understood as a complex trait of dealing with stress, indicating the individual's ability to change their way of thinking and acting in a difficult situation according to the criterion of effectiveness. In the adult version, the operationalized variable consists of three dimensions: repertoire, changeability and reflexivity. If the subject achieves a high score on the Repertoire subscale, he/she is convinced of having a wide repertoire of stress management methods and the ability of finding appropriate or new countermeasures and applying them in the face of new difficulties. The individual perceives himself as a competent person in the field of stress coping. When the examined person obtains a high result in the Changeability subscale, he/ she is willing to use the kind of stress coping strategies that will provide him/her an effective solution. When he/she notices that the applied method is ineffective, he/she changes it. An individual is prepared to look for an adequate coping method and use different psychological and behavioural coping strategies interchangeably. A high result in the Reflexivity subscale shows that the individual is able to reflect on the strategies applied for dealing with stress in the aspect of accepted values and also to accept the difficult situation in which he or she has found him or herself (Borzyszkowska \& Basińska, 2018; Góralska \& Basińska, 2019; Stępka-Tykwińska, Basińska, Soltys, \& Piórowska, 2019).

The exploratory variables were variables that measure the intensity of three personal resources: psychological resiliency, hope and spiritual wellbeing.

Resiliency is defined as a personality trait or a relatively long-lasting individual potential that facilitates its elastic adaptation to changing environmental conditions (Ogińska-Bulik, 2011). According to another definition, resiliency may be understood in terms of effective adaptation to stressful events and life difficulties (Piórowska, Basińska, Piórowski, \& Janicka, 2017). In the presented study, we accepted a definition of resiliency proposed by Ogińska-Bulik and Juczyński (2008). In this respect, resiliency is understood in the categories of a self-regulation 
mechanism. It is made up of behavioural, cognitive and emotional factors. The behavioural aspects of resiliency include applying diverse coping strategies in stressful situations and also a readiness to seek new experiences. The cognitive component is the individual's belief in their own effectiveness and the perception of difficult situations as challenges. The emotional aspect of resiliency concerns above all emotional stability and positive affect (Borzyszkowska \& Basińska, 2018).

Hope is not an emotional state, but a "cognitive motivational process" (Snyder, 2002; Łaguna, Trzebiński, \& Zięba, 2005, p. 8). It consists of two beliefs: (1) about having a strong will, agency, goal-directed energy, and (2) about the ability to find solutions and plan ways to accomplish goals, pathway. Agency reflects the individual's belief in their ability to use created strategies and persevere along the path that leads to the goal. The belief in ability to find solutions refers perceiving oneself as an entity, who is capable of generating one or many possible paths (strategies, ways, plans) to achieve a goal.Spiritual well-being conceptualises the effect of spirituality on subjective well-being (Daaleman \& Frey, 2004). Intensity of spiritual well-being reflects cognitive representation of one's ability to ask and answer major existential questions. Spirituality as a human drive, ability to making sense of self and the world is not necessarily associated with religion. It is defined as "a congruent, meaningful life scheme and high functional selfefficacy beliefs that synergistically promote personal agency" (Frey, Daaleman, \& Payton, 2005, p. 561).

\section{RESEARCH METHODS}

The following study methods were applied: the Resiliency Measurement Scale (SPP-25) by OgińskaBulik and Juczyński (2008), the Adult Hope Scale (AHS) by Snyder in its Polish adaptation by Łaguna, Trzebiński, and Zięba (2005), the Spirituality Index of Well-Being (SIWB) by Daaleman and Frey in its Polish adaptation by Sołtys and Basińska (in print), the Flexibility in Coping with Stress Questionnaire (FCSQ-14) by Basińska et al. (in print) and the Global Measure of Perceived Stress by Cohen, Kamarck and Mermelstein in its Polish adaptation by Juczyński and Ogińska-Bulik (2009). A brief description of these tools is presented below.

The Resiliency Measurement Scale (SPP-25) is designed to measure resiliency as a capability of one's personality. It consists of 25 statements, to which these individuals respond by means of a 5-point Likert scale. SPP-25 includes five factors: (1) Determination and persistence in action, (2) Openness to new experiences and a sense of humour, (3) Personal competencies to cope and tolerance of negative emotions, (4) Tolerance of failures and treating life as a challenge, and (5) Optimistic life attitude and ability to mobilise in difficult situations. The scale has satisfactory psychometric properties - Cronbach's $\alpha$ for the sub-scales ranged from .67 to .75, while for the overall result, the coefficient equalled .89 (Ogińska-Bulik \& Juczyński, 2008). In our own studies that involved cancer patients, the reliability was lower and ranged from .66 to .74. For total resiliency, Cronbach's $\alpha$ was .91 .

The Adult Hope Scale (AHS) consists of 12 items (8 diagnostic statements and 4 fillers) to which the respondents answered using the 8-point Likert scale. It is composed of two subscales measuring one's perception of agency and pathways to find solutions. The reliability of the Polish version of the scale, measured by means of Cronbach's $\alpha$, equalled .82 (Eaguna et al., 2005). In our own studies, the reliability coefficients were .72 and .78 for the agency and pathways, respectively, and the total result was .85 .

The Spirituality Index of Well-Being (SIWB) is designed to study the universally understood spirituality. The scale consists of 12 items to which the respondents answered using a 5-point Likert scale. The scale is composed of 2 subscales: Self-Efficacy and Life Scheme. The tool has satisfactory psychometric properties (Daaleman \& Frey, 2004). In the research involving cancer patients, Cronbach's $\alpha$ equalled .83 and .84, respectively, for the self-efficacy and life scheme subscales, and .87 for overall spiritual well-being.

The Flexibility in Coping with Stress Questionnaire (FCSQ-14) consists of 14 items, to which the respondents answer by selecting one of the following answers: 0 (never), 1 (sometimes), 2 (often) and 3 (always). The higher the test score, the more flexible the respondent is in terms of coping with stress. The questionnaire consists of three subscales. In the version for adults, the following subcategories are distinguished: repertoire, changeability and reflexivity. The tool is accurate and reliable (Basińska et al., in print; Borzyszkowska \& Basińska, 2018; StępkaTykwińska et al., 2019). In our study, which involved a group of cancer patients, the reliability coefficients for the Repertoire, Changeability and Reflexivity were $.79, .85$ and .68 , respectively, and for the total score, .91 .

The Global Measure of Stress Scale by Cohen, Kamarck, and Mermelstein in its Polish adaptation by Juczyński and Ogińska-Bulik (2009). The tool is used to measure the degree to which situations in one's life are appraised as stressful. The scale consists of 10 questions concerning various subjective feelings associated with problems, personal events, behaviour and coping strategies. These questions relate to the appraisal of the intensity of stress related to one's own life situation during the last month, as well as to the effectiveness of coping with it. The total score is the sum of all points, the theoretical distribution of which ranges from 0 to 40 ; the higher the
Personal resources and flexibility in coping in a group of cancer patients 
score, the greater the intensity of sense of stress. The reliability of the scale measured by Cronbach's $\alpha$ in cancer patients was .75 .

\section{RESULTS}

The analysis of descriptive statistics (Table 1) demonstrated that in the surveyed sample of cancer patients, the mean resiliency score corresponded to

Małgorzata

A. Basińska, Michalina Sołtys a sten score of 7 , and similarly, the mean of the total level of hope and its subscales - agency and pathways - corresponded to a sten score of 6 . A stronger component of spiritual well-being was the life scheme that indicated the sense of purpose rather than the sense of self-efficacy and responsibility for one's life. The mean score for flexibility in coping, in the repertoire and changeability subscales, corresponded to a sten score of 6 , while for the reflexivity scale it corresponded to a sten score of 7 .

The values of skewness and kurtosis for most of the analysed variables (except for hope) do not exceed the absolute value of 1 , which proves that the distributions are close to normal and warrant the use of parametric tests (Bedyńska \& Książek, 2012). A non-parametric test was used in analyses which took hope into account.

\section{PERSONAL RESOURCES (HOPE, RESILIENCY, SPIRITUAL WELL-BEING) AND FLEXIBILITY IN COPING IN CANCER PATIENTS}

Pearson and Spearman correlation analyses were conducted to verify the first research hypothesis, which assumed the existence of a positive, statistically significant relationship between resiliency, hope, and spiritual well-being, including their subdimensions, and the aspects of flexibility in coping (Table 2).

The repertoire correlated positively at a statistically significant level with all the analysed resources: moderately with resiliency, and poorly with hope and spiritual well-being. Changeability correlated positively at a statistically significant level with resiliency and spiritual well-being. However, it did not correlate with hope and its subscales. Reflexivity had the least statistically significant relationships with the analysed resources in the surveyed group - it correlated poorly with several dimensions of resiliency and life scheme, and was not related to hope. In general, flexibility correlated moderately or poorly with all the examined resources. In addition, a multiple linear regression analysis was performed (using the progressive method - applying ridge regression to minimise collinearity), taking into account

Table 1

Descriptive statistics of analysed variables $(N=108)$

\begin{tabular}{|c|c|c|c|c|c|c|}
\hline Variables & M & $S D$ & Min & Max & SKE & $\mathrm{K}$ \\
\hline Perseverance and determination in action & 16.14 & 2.89 & 8 & 20 & -0.50 & -0.33 \\
\hline Openness to new experiences and a sense of humour & 16.71 & 2.36 & 10 & 20 & -0.33 & -0.35 \\
\hline Ability to cope with and tolerate negative emotions & 15.31 & 2.68 & 9 & 20 & -0.10 & -0.58 \\
\hline Ability to tolerate failures and view life as a challenge & 15.96 & 2.47 & 10 & 20 & -0.14 & -0.64 \\
\hline Optimism in life and ability to face adversities & 14.61 & 2.99 & 6 & 20 & -0.07 & -0.08 \\
\hline Resiliency - global result & 78.73 & 11.21 & 50 & 100 & -0.14 & -0.42 \\
\hline Agency thinking & 25.63 & 4.22 & 7 & 32 & -1.13 & 3.03 \\
\hline Pathways thinking & 26.39 & 4.30 & 7 & 32 & -1.24 & 3.68 \\
\hline Hope - global result & 52.02 & 7.81 & 14 & 64 & -1.52 & 3.41 \\
\hline Self-efficacy* & 20.63 & 5.39 & 8 & 30 & -0.51 & -0.37 \\
\hline Life scheme* & 25.59 & 4.33 & 11 & 30 & -1.06 & 0.66 \\
\hline Spiritual well-being - global result* & 46.21 & 8.55 & 22 & 60 & -0.74 & 0.30 \\
\hline Sense of stress ${ }^{*}$ & 17.42 & 6.41 & 4 & 36 & 0.30 & -0.07 \\
\hline Repertoire & 8.69 & 3.11 & 3 & 15 & 0.20 & -0.82 \\
\hline Changeability & 10.72 & 3.92 & 1 & 18 & 0.05 & -0.64 \\
\hline Reflexivity & 6.01 & 2.05 & 1 & 9 & -0.27 & -0.59 \\
\hline Flexibility in coping - global result & 25.43 & 8.13 & 5 & 42 & 0.09 & -0.77 \\
\hline
\end{tabular}

Note. ${ }^{*} \mathrm{~N}=107, \mathrm{SKE}-$ skewness, $\mathrm{K}-$ kurtosis. 
Table 2

Relationship between personal resources (resiliency, hope, spiritual well-being) and coping flexibility in the group of cancer patients

\begin{tabular}{|c|c|c|c|c|}
\hline \multirow[t]{2}{*}{ Personal resources } & \multicolumn{4}{|c|}{ Flexibility in coping } \\
\hline & Repertoire & $\begin{array}{c}\text { Change- } \\
\text { ability }\end{array}$ & Reflexivity & $\begin{array}{c}\text { Global } \\
\text { result }\end{array}$ \\
\hline Perseverance and determination in action & $.38^{* * *}$ & $.25^{* *}$ & .17 & $.31^{* * *}$ \\
\hline Openness to new experiences and a sense of humour & $.47^{* * *}$ & $.34^{* * *}$ & $.30 * * *$ & $.42^{* * *}$ \\
\hline Ability to cope with and tolerate negative emotions & $.40 * *$ & $.31^{* * *}$ & .18 & $.35^{* * *}$ \\
\hline Ability to tolerate failures and view life as a challenge & $.39^{* * *}$ & $.25^{*}$ & $.22^{*}$ & $.32^{* * *}$ \\
\hline Optimism in life and ability to face adversities & $.44^{* * *}$ & $.24^{*}$ & $.23^{*}$ & $.34^{* * *}$ \\
\hline Resiliency - global result & $.50 * * *$ & $.33^{* * *}$ & $.26^{* *}$ & $.41^{* * *}$ \\
\hline Agency thinking ${ }^{R}$ & $.29^{* *}$ & .17 & .13 & $.23^{*}$ \\
\hline Pathways thinking ${ }^{\mathrm{R}}$ & $.25^{*}$ & .16 & $.22^{*}$ & $.22^{*}$ \\
\hline Hope - global result ${ }^{R}$ & $.31^{* * *}$ & .19 & .19 & $.25^{* *}$ \\
\hline Self-efficacy & $.34^{* * *}$ & $.23^{*}$ & .07 & $.26^{* * *}$ \\
\hline Life scheme & $.33^{* * *}$ & $.33^{* * *}$ & $.22^{*}$ & $.34^{* * *}$ \\
\hline Spiritual well-being - global result & $.38^{* * *}$ & $.31^{* * *}$ & .15 & $.33^{* * *}$ \\
\hline
\end{tabular}

Personal resources and flexibility in coping in a group of cancer patients the sub-dimensions of hope, resiliency and spiritual well-being.

The model of multiple linear regression obtained in step 4, explaining $23 \%$ changeability of coping flexibility, was statistically significant $F(4,102)=8.81, p<.001$, adjusted $\left.R^{2}=.23\right)$. However, the only significant predictor was the life scheme $(\beta=.26, p=.002)$, while the model explaining the Repertoire of coping strategies obtained in step 6 $\left(F(6,100)=9.05, p<.001\right.$, adjusted $\left.R^{2}=.31\right)$ explained $31 \%$ of this dependent variable. Two subscales of resiliency proved to be significant but poor predictors. These were Openness to new experiences and a sense of humour $(\beta=.21, p=.016)$ and Optimistic life attitude, and ability to mobilise in difficult situations $(\beta=.22, p=.031)$, as well as a meaningful life scheme $(\beta=.21, p=.021)$. Similarly, the model for strategy changeability obtained in step 3 $\left(F(3,103)=8.26, p<.001\right.$, adjusted $\left.R^{2}=.17\right)$ explained $17 \%$ of the variance in results. The one important predictor was the life scheme $(\beta=.26, p=.003)$. The only predictor of Reflexivity in the model, explaining $9 \%$ of variation $(F(2,104)=6.12, p=.003$, corrected $R^{2}=.09$ ), was Openness to new experiences and a sense of humour $(\beta=.24, p=.009)$. In addition, the multiple regression analysis, taking into account the total scores for the selected resources, demonstrated that resiliency $(\beta=.41, p<.001)$ and spiritual well-being $(\beta=.29, p=.001)$ explain $23 \%$ of variation in coping flexibility $(F(3,103)=11.43$, $p<.001$, adjusted $R^{2}=.23$ ). Hope was not a significant predictor. The obtained results warrant partial acceptance of $\mathrm{H} 1$.

\section{PATTERNS OF PATIENTS' PERSONAL RESOURCES AND THEIR FLEXIBILITY IN COPING}

The cluster analysis allowed 2 or 3 clusters to be identified; however, due to the very non-equivalent classification of the respondents, categorisation into two groups was selected: (1) people with more resources $(n=52)$ and (2) patients with less individual resources $(n=55)$. The analysis of surveyed patients showed statistically significant differences between cluster classifications in respect of all the analysed resources (Table 3).

Next, we examined whether the classification to a specific cluster differentiates the intensity of coping flexibility in the group oncological patients. Investigation results of the normal distribution of variables and the analyses of homogeneity of variance suggested use of the Mann-Whitney $U$ test for analyses considering the subscales of Reflexivity, and Student's $t$-test for the remaining variables. The analyses of the different significance tests demonstrated that people with more intensive resources were characterised by greater coping flexibility (a sten score of 7) (Table 4). In conclusion, H2 was accepted. 
Table 3

Results of variance analysis of sub-dimensions of analysed resources by classification into a cluster with more or less resources available

\begin{tabular}{|c|c|c|c|c|c|c|c|c|}
\hline \multirow[t]{2}{*}{ Variables } & \multicolumn{2}{|c|}{ Cluster 1} & \multicolumn{2}{|c|}{ Cluster 2} & \multirow{2}{*}{$\begin{array}{l}\text { Inter- } \\
\text { group } \\
\text { SS }\end{array}$} & \multirow{2}{*}{$\begin{array}{l}\text { Intra- } \\
\text { group } \\
\text { SS }\end{array}$} & \multirow[t]{2}{*}{$F$} & \multirow[t]{2}{*}{$p$} \\
\hline & $M$ & $S D$ & $M$ & $S D$ & & & & \\
\hline $\begin{array}{l}\text { Perseverance and determination } \\
\text { in action }\end{array}$ & 17.25 & 2.63 & 15.02 & 2.69 & 133.14 & 744.73 & 18.77 & $<.001$ \\
\hline $\begin{array}{l}\text { Openness to new experiences } \\
\text { and a sense of humour }\end{array}$ & 18.12 & 1.69 & 15.42 & 2.16 & 194.45 & 396.69 & 51.47 & $<.001$ \\
\hline $\begin{array}{l}\text { Ability to cope with and tolerate } \\
\text { negative emotions }\end{array}$ & 16.65 & 2.33 & 14.04 & 2.40 & 183.14 & 587.70 & 32.72 & $<.001$ \\
\hline $\begin{array}{l}\text { Ability to tolerate failures and } \\
\text { view life as a challenge }\end{array}$ & 17.31 & 2.00 & 14.65 & 2.19 & 188.15 & 461.51 & 42.81 & $<.001$ \\
\hline $\begin{array}{l}\text { Optimism in life and ability to } \\
\text { face adversities }\end{array}$ & 16.27 & 2.29 & 13.09 & 2.75 & 270.01 & 676.78 & 41.89 & $<.001$ \\
\hline Agency thinking & 27.92 & 2.91 & 23.40 & 4.11 & 546.83 & 1342.89 & 42.76 & $<.001$ \\
\hline Pathways thinking & 28.62 & 2.75 & 24.31 & 4.51 & 495.67 & 1484.05 & 35.07 & $<.001$ \\
\hline Self-efficacy & 23.52 & 3.88 & 17.89 & 5.21 & 846.72 & 2232.33 & 39.83 & $<.001$ \\
\hline Life scheme & 28.04 & 2.37 & 23.27 & 4.51 & 607.07 & 1382.83 & 46.10 & $<.001$ \\
\hline
\end{tabular}

Małgorzata

A. Basińska, Michalina Sołtys

Note. Intergroup SS - intergroup sum of squares, Intragroup SS - variation inside groups.

Table 4

Significance of differences between patients with varying intensity of individual resources in terms of coping flexibility $(d f=105)$

\begin{tabular}{|c|c|c|c|c|c|c|}
\hline \multirow[t]{2}{*}{ Flexibility in coping } & \multicolumn{2}{|c|}{$\begin{array}{l}\text { Patients with more } \\
\text { resources }(n=52)\end{array}$} & \multicolumn{2}{|c|}{$\begin{array}{l}\text { Patients with less } \\
\text { resources }(n=55)\end{array}$} & \multirow[t]{2}{*}{$t / z$} & \multirow[t]{2}{*}{$p$} \\
\hline & M & $S D$ & M & $S D$ & & \\
\hline Flexibility in coping - global result & 28.81 & 8.30 & 22.07 & 6.48 & $4.69^{t}$ & $<.001$ \\
\hline Repertoire & 10.21 & 3.02 & 7.22 & 2.45 & $5.64^{t}$ & $<.001$ \\
\hline Changeability & 12.04 & 3.95 & 9.40 & 3.46 & $3.68^{t}$ & $<.001$ \\
\hline Reflexivity & 6.56 & 2.12 & 5.45 & 1.85 & $2.94^{z}$ & .003 \\
\hline
\end{tabular}

PERSONAL RESOURCES AND COPING FLEXIBILITY DEPENDING ON THE STRESS PERCEIVED BY THE RESPONDENTS

The third tested hypothesis assumed that the relationship between cancer patients' resources (resiliency, hope, spiritual well-being) and coping flexibility was modified by their appraisal of the perceived stress. To this end, a series of 48 hierarchical regression analyses were performed using the PROCESS macro implemented as an add-on to SPSS Statistics 25. It has an advantage in that it does not require the assumption of normality to be met due to the applied resampling procedure, and also in that it allows for the performance of analyses on relatively small samples (Preacher \& Hayes, 2004; Hayes, 2012). The effects for which the confidence interval (95\%) excluded 0 were considered as significant ${ }^{1}$.

Due to the extensiveness of these analyses, and for the sake of clarity of the presented findings, only statistically significant results are presented below. A series of analyses involving the perceived stress level as a moderator revealed only two interactive effects - which were of borderline significance. The first concerned the relationship between the sub-dimension of resiliency: tolerance of failures and treating life as a challenge, and changeability of strategies, while the other concerned the relationship between the general resiliency score and changeability.

The model which took into account the interaction between the perceived stress and the abovementioned sub-dimension of resiliency proved to 
be statistically significant $(F(3,102)=5.68, p=.001$, $\left.R^{2}=.14\right)$ and explained $12 \%$ of variance in the dependent variable. With the moderator included, the change in the coefficient of determination was $3 \%$. The interaction effect was found to be of borderline significance $(p=.052)$, and the confidence interval included 0 , although it did not exceed its value.

The model involving the perceived stress level as a moderator of the relationship between resiliency and strategy changeability was also statistically significant $\left(F(3,102)=6.28, p=.001, R^{2}=.16\right)$, and explained $13 \%$ of variance in the dependent variable. With the moderator included, the change in the coefficient of determination was $3 \%$. The interaction effect was of borderline significance $(p=.051)$.

In order to determine the observed trends, a simple linear regression analysis was conducted in the following subgroups: those who experienced lower $(n=52)$ and higher $(n=54)$ stress. The respondents were divided based on the mean $(M=17.45)$. A comparison of model fitting (the relationship between resiliency and its sub-dimension, and changeability) in the groups with lower and higher levels of perceived stress is presented in Table 5.

As indicated by the results of the analyses, the group of people who experienced lower stress levels demonstrated a moderately positive relationship between tolerance of failures, treating life as a challenge, and coping flexibility in respect of changeability of strategies $(\beta=.42, p=.002)$. In the group of cancer patients who experienced higher stress levels, no statistically significant correlation between the two variables was found $(\beta=.24, p=.070)$. The strength of relationship between the total resiliency score and the changeability of coping strategies in the groups of people with lower and higher levels of stress was comparable, but slightly lower in the group of people with higher levels of stress. The results suggest that treating life as a challenge can be a resource favouring stress coping changeability at lower levels of perceived stress. However, the results of all the conducted analyses warrant the rejection of $\mathrm{H} 3$.

\section{DISCUSSION}

Cancer patients very often experience symptoms of emotional stress which appear as anxiety, depression and anger (Juczyński, 2002), resulting from the nature of the disease itself and the course of its treatment. The severe and often incurable disease causes a substantial physical and emotional strain. In order to adjust to this situation, it is necessary for patients to use their personal resources in the coping process (Spendelow et al., 2018). According to Hobfoll (1998), these resources may include not only objects, but also certain conditions, personality traits and energy resources, which directly contribute to survival, or which are used to acquire other, specific resources, indirectly contributing to the adjustment of the individual.

In this context, coping flexibility appears to be a desirable attribute for cancer patients. This is because of, inter alia, the highly dynamic changes in their health as a result of the trajectory of the disease and its treatment. The existing research results have supported the hypothesis that the nature of the applied coping strategies is related to other aspects of the patient's functioning, including less severe symptoms of depression (Kato, 2001, 2015), better general mental health (Saito \& Kamimura, 2011), and well-being. Consequently, patients with greater flexibility in coping demonstrated a higher quality of life (Cheng et al., 2012) and could more easily resolve difficulties encountered in the treatment process (Reese et al., 2010; Spendelow et al., 2018), thus gaining secondary protection against other disorders (Kirsh et al., 2004).

In our studies, the patients obtained average scores in flexibility in coping (sten score of 6), suggesting a similarity to the results attained previously in this group of patients (Basińska et al., 2017), despite the use of a different measurement method.

The aim of the discussed study was to investigate whether patients who have more resources (are more resilient, more hopeful and enjoy spiritual well-being) are also characterised by greater coping flexibility. For this purpose, correlation analysis, regression analysis and cluster analysis were performed. The study demonstrated that coping flexibility in cancer patients correlated positively, to a moderate or low degree, with all the analysed resources, including all their sub-dimensions. These results suggest that having personal resources can promote coping flexibility, but the role of these resources varies. The regression analysis also demonstrated that the role of resources in predicting coping flexibility may vary. The life scheme is the most significant predictor of coping flexibility and its dimensions (except for Reflexivity). Daaleman and Frey (2004) consider the life scheme as a cognitive representation of one's life which provides the individual with a sense of meaning and purpose. The belief in having a broad repertoire of coping strategies and the ability to change them depending on the situation and the efficacy of coping may be conducive to constructing a more appropriate representation of life goals. Openness to new experiences and a sense of humour also proved to predict the intensity of the majority of coping flexibility dimensions (except for Changeability). Openness to new experiences and the ability to perceive the humorous aspects of situations may, on the one hand, predispose patients to have a broader range of coping strategies and, on the other hand, foster their ability to reflect on and consider alternative ways of coping with difficult situations. Another dimension of resiliency - the Optimistic life attitude and ability
Personal resources and flexibility in coping in a group of cancer patients 
to mobilise in difficult situations - facilitates the positive perception of oneself, one's abilities, and broadening of the repertoire of one's own coping strategies. It is conceivable that a wide range of coping strategies may also reassure an individual (in a feedback loop) in his or her optimistic attitude to life, so that he or she feels empowered to face the upcoming difficulties (cf. Fredrickson, 2004). The relationships of coping flexibility are undoubtedly the strongest with resiliency, which means the ability to cope with difficult situations refers to a set of features such as ingenuity, resourcefulness and firmness. These relationships are much weaker in relation to hope, which is understood as expecting positive results of one's actions (Eaguna et al., 2005). Perhaps the time perspective is of key importance to understanding the revealed relationships. Resiliency concerns a property that is revealed at a specific time and place of a problematic situation, while hope refers to the future, to the expectation of changes for the better. In this context, the stronger relationship between resiliency and flexibility in coping, which requires an ongoing reappraisal of one's coping strategies and the employment of new strategies as soon as they appear to be ineffective, is more understandable (cf. Lazarus \& Folkman, 1984; Kato, 2015; Basińska et al., 2017).

It is also worth noting the meaning of constructs of people with a high level of agency (a dimension of hope) who are convinced that they can initiate and sustain the necessary actions. This is particularly relevant when an individual encounters obstacles and difficulties, as it provides the necessary motivation to act (Snyder, 2002). It appears, however, that it may also contribute to rigidity and to a certain inability to deviate from the applied way of coping. Similarly, the results of surveys among police officers revealed the lack of relationship between the dimension of hope agency and coping flexibility (Piórowska \& Banasik, 2015). This interpretation also seems to be supported by the theoretical assumptions related to the effectiveness of the stress transaction. It is emphasised that one of the key aspects of coping adaptability is the ability to reappraise the stress situation, following secondary appraisal. This refers to the appraisal based on feedback from the environment, as well as on the individual's response to the application of specific coping strategies. An important aspect of reappraisal is the ability of an individual to abandon previous, ineffective coping techniques in favour of other strategies conducive to successful coping with stress (Lazarus \& Folkman, 1984).

The relationships between coping flexibility and spirituality are slightly stronger than between coping flexibility and hope, but weaker than between coping flexibility and resiliency. Therefore, the belief in one's own ability to cope with difficult situations and take responsibility for one's actions (self-efficacy), as well as the belief in their purposefulness (life scheme), contributes more than the expectation of positive results in the future to the sustainability of the belief that the person has a sufficient repertoire of strategies to apply at the right time.

Similarly, the results of a multiple regression analysis confirmed that resiliency and spiritual well-being (as opposed to hope) are resources that together foster coping flexibility. Their mutual involvement is particularly evident in relation to predicting a wide range of coping strategies. An individual with a broader repertoire of coping strategies not only has confidence in the purposefulness and order of his or her life, but is also open to change, optimistic and able to mobilise himself or herself in difficult situations.

The cluster analysis led to the classification of the surveyed patients into those with lower and higher intensity of resources. Indeed, those who had more resources were able to cope more flexibly. It is worth recalling here that, as proposed by Hobfoll (1998), all conditions, competencies and abilities of an individual which directly contribute to their survival or to gaining other resources, indirectly contributing to the adaptation of that individual, may be called resources. In this sense, coping flexibility is a resource and can be applied in relation to chronic somatic diseases. It would appear that the fact of becoming ill determines a deterioration of the patient's situation in all aspects of his or her life. This is not always the case, mainly due to the resources which can be found within the individual or in his or her environment. These can affect his or her functioning in disease to a much greater extent and steer it in a different direction than it would appear from the characteristics of a given disease. A person suffering from cancer, despite the loss of health as an important resource, can effectively use his or her multiple resources to cope with the disease. By extension, the disease will have a much less negative impact on the functioning of such an individual when compared to a person who has fewer personal resources and is, therefore, less efficacious in coping.

The nature of the relationship between the personal resources of cancer patients and their coping flexibility is explained in more detail by the results of in-depth analyses taking into account stress as a moderator. Both the present and previous results (Basińska et al., 2017), obtained using other measurement methods, demonstrated that perceived stress does not modify the relationship between resiliency, hope and spiritual well-being, including its dimensions, and coping flexibility. The two interaction effects obtained were of borderline significance. It was expected that individuals experiencing higher levels of stress would become more rigid and much less flexible compared to those experiencing lower levels of stress. The results encourage the search for a way of understanding the construct of coping flexibility in relation to stress. 
Since this is a novel construct, the question of its nature is important. Given the relationships between coping flexibility and personal resources (cf. Basińska, 2015; Piórowska \& Banasik, 2015), flexible coping also appeared to be a resource. However, the obtained correlation and regression coefficients (mostly low) make it necessary to consider other explanations as well. Another perspective that should be taken into account involves executive functions. This term refers to the many strictly cognitive aspects of functioning, including cognitive flexibility (whose relationship with coping flexibility is significant (cf. Basińska et al., in print) and problem solving (Jurado \& Rosselli, 2007). These functions should be defined in terms of their role and the outcome they lead to. This outcome is flexible (i.e. effective) coping, while the lack of flexibility was identified as an important barrier to problem solving (Zelazo, Müller, Frye, \& Marcovitch, 2003).

\section{CONCLUSIONS}

To sum up the results of this study, it should be stressed that the role of the discussed personal resources varied in the surveyed sample of patients. Resiliency and spiritual well-being were the resources which clearly promoted coping flexibility. The particularly important aspects of flexibility in coping strategies were: one's belief in the order and purposefulness of life, as well as openness to new experiences and the ability to perceive the humorous aspects of difficult situations. In contrast to the results of previous studies, which were obtained using a different method, hope had a weaker relationship with coping flexibility. It was also not confirmed that the subjective sense of stress modified the ability to use hope as a resource to cope with stress more flexibly. However, a simple association between resiliency and flexibility could be confirmed (Basińska et al., 2017). The results were undoubtedly influenced by the limitations of the research. One of these limitations involved the excessively high values of kurtosis for hope, which, despite the selection of cases, remained at an unsatisfactory level (confidence intervals were not bootstrapped at the level of simple linear regression analyses). This fact was partly reflected in the poor correlation between hope and coping flexibility. Another limitation of this study was the non-homogeneity of the group of cancer patients in respect of diagnosis and duration of the disease. From an informative point of view, it is recommendable to continue the study among cancer patients to allow for the analysis of more homogeneous groups. Despite the aforementioned limitations, the obtained results are a source of clinical implications having importance from the perspective of psychological interventions addressed to cancer patients. Patients characterised by greater resource intensity are clearly more flexible in coping with stress in all its dimensions. As the flexibility of coping strategies serves to improve efficacy and adaptation to difficult situations (Cheng, 2001; Kato, 2015; Basińska et al., in print), affecting both mental and physical health (Reese et al., 2010; Saito \& Kamimura, 2011; Cheng et al., 2012) in a feedback loop, it is worth supporting patients in developing their personal resources such as resiliency, hope and spiritual well-being.

\section{ACKNOWLEDGEMENTS}

This work is supported by the National Center for Science (grant number 2016/21/B/HS6/03786).

\section{ENDNOTE}

1 For the interpretation of the results, a bias-corrected confidence interval was used, which is usually recommended (Hayes, 2012).

\section{References}

Ashraf, G. M., Azhar, A., Ali, A., Rehan, M., Zia, Q., Owais, M., Alexiou, A., Rauf, A., Ganash, M., Kamal, M. A., \& Rajeh, N. (2018). Relationship between CNS and immunology in relation to psychology. Current Drug Metabolism, 19, 847-855. https://doi.org/10.2174/1389200219666180129142534.

Basińska, M. A. (2015) (Ed.). Coping flexibility with stress in health and in disease. Elastyczne radzenie sobie ze stresem w zdrowiu $i$ w chorobie. Bydgoszcz: Wydawnictwo UKW.

Basińska, M. A., Sołtys, M., Kruczek, A., Grzankowska, I., Borzyszkowska, A., Janicka, M., Góralska, K., \& Stępka-Tykwińska, E. (in print). Flexibility in coping with stress questionnaire: structure and psychometric characteristics.

Basińska, M. A., Sołtys, M., Kwiatkowska, J., Peplińska, S., Borzyszkowska, A., \& Kawiecka-Dziembowska, B. (2017). Zasoby osobiste - prężność i nadzieja - a elastyczność w radzeniu sobie: moderująca rola poczucia stresu [Personal resources - resiliency and hope - and coping flexibility among oncological patients: moderating role of the sense of stress]. Psychoonkologia, 21, 100-112. https://doi.org/10.5114/pson.2017.77298

Bedyńska, M., \& Książek, S. (2012). Statystyczny drogowskaz 3 [Statistical signpost 3]. Warszawa: Wydawnictwo Akademickie Sedno.

Borzyszkowska, A., \& Basińska, M. A. (2018). Personal resources - resiliency, hope and spiritual wellbeing in relation to coping flexibility with stress in alcohol dependent persons. Alcoholism and Drug Addiction, 31, 243-264. https://doi.org/10.5114/ain.2018.83912
Personal resources and flexibility in coping in a group of cancer patients 
Burton, C. L., Yan, O. H., Pat-Horenczyk, R., Chan, I. S., Ho, S., \& Bonanno, G. A. (2012). Coping flexibility and complicated grief: a comparison of American and Chinese samples. Depression and Anxiety, 29, 16-22. https://doi.org/10.1002/da.20888

Cheng, C. (2001). Assessing coping flexibility in real-life and laboratory settings: a multimethod approach. Journal of Personality and Social Psychology, 80, 814-833. https://doi.org/10.1037/00223514.80.5.814

Matgorzata

A. Basińska, Michalina Sołtys

Cheng, C., Chan, N.Y., Chio, J. H., Chan, P., Chan, A. O., \& Hui, W. M. (2012). Being active or flexible? Role of control coping on quality of life among patients with gastrointestinal cancer. Psycho-Oncology, 21, 211-218. https://doi.org/10.1002/pon.1892

Chirico, A., Serpentini, S., Merluzzi, T., Mallia, L., Del Bianco, P., Martino, R., Trentin, L., Bucci, E., De Laurentiis, M., Capovilla, E., Lucidi, F., Botti, G., \& Giordano, A. (2017). Self-efficacy for coping moderates the effects of distress on quality of life in palliative cancer care. Anticancer Research, 37, 1609-1615. https://doi.org/10.21873/anticanres.11491

Curtis, R., Groarke, A., McSharry, J., \& Kerin, M. (2014). Experience of breast cancer: Burden, benefit, or both? Cancer Nursing, 37, e21-e30. https:// doi.org/10.1097/NCC.0b013e3182894198

Daaleman, T. P., \& Frey, B. B. (2004). The Spirituality Index of Well-Being: a new instrument for healthrelated quality of life research. Annals of Family Medicine, 2, 499-503. https://doi.org/10.1370/afm.89

D’Acquisto, F. (2017). Affective immunology: Where emotions and the immune response converge. Dialogues in Clinical Neuroscience, 19, 9-19.

Fredrickson, B. (2004). The broaden-and-build theory of positive emotions. Philosophical Transactions of the Royal Society of London. Series B, 359, 13671378. https://doi.org/10.1098/rstb.2004.1512

Frey, B. B., Daaleman, T. P., \& Peyton, V. (2005). Measuring a dimension of spirituality for health research: Validity of the Spirituality Index of WellBeing. Research on Aging, 27, 556-577. https://doi. org/10.1177/0164027505277847

Gilbar, O. (2003). Do attitude toward cancer, sense of coherence and family high risk predict more psychological distress in women referred for a breast cancer examination? Women Health, 38, 35-46. https://doi.org/10.1300/J013v38n02_03

Góralska, K., \& Basińska, M. A. (2019). Resiliency as a predictor of flexibility in coping with stress of cardiac patients. Health Psychology Report, 7, 191-199. https://doi.org/10.5114/hpr.2019.85952

Hayes, A. F. (2012). PROCESS: a versatile computational tool for observed variable mediation, moderation, and conditional process modeling. Retrieved from http://www.afhayes.com/public/process2012.pdf

Hobfoll, S. E. (1998). Stress, culture, and community. The psychology and philosophy of stress. New York: Plenum Press.
Izydorczyk, B., Kwapniewska, A., Lizińczyk, S., \& Sitnik-Warchulska, K. (2019). Characteristics of psychological resilience and body image in women in the early and late periods after mastectomy. Health Psychology Report, 7, 32-47. https://doi.org/10.5114/ hpr.2018.79996

Jimenez-Fonseca, P., Calderón, C., Hernández, R., Ramón, Y., Cajal, T., Mut, M., \& Carmona-Bayonas, A. (2018). Factors associated with anxiety and depression in cancer patients prior to initiating adjuvant therapy. Clinical \& Translational Oncology, 20, 1408-1415. https://doi.org/10.1007/s12094018-1873-9

Juczyński, Z. (2002). Psycho-oncology as a field of clinical research and practice. Psychoonkologia, 3, 71-75.

Juczyński, Z., \& Ogińska-Bulik, N. (2009). Tools for measuring stress and coping with stress. Warszawa: Pracownia Testów Psychologicznych PTP.

Jurado, M. B., \& Rosselli, M. (2007). The elusive nature of executive functions: a review of our current understanding. Neuropsychology Review, 17, 213233. https://doi.org/10.1007/s11065-007-9040-z

Kato, T. (2001). The relationship between flexibility of coping to stress and depression. Japanese Journal of Psychology, 72, 57-63. https://doi.org/10.4992/ jjpsy. 72.57

Kato, T. (2015). The dual-process theory: New approach to coping flexibility. In M. A. Basińska (Ed.), Coping flexibility with stress in health and in disease. Elastyczne radzenie sobie ze stresem w zdrowiu i w chorobie (pp. 19-37). Bydgoszcz: Wydawnictwo UKW.

Kirsh, K. L., McGrew, J. H., \& Passik, S. D. (2004). Difficulties in screening for adjustment disorder, Part II: An attempt to develop a novel self-report screening instrument in cancer patients undergoing bone marrow transplantation. Palliative \& Supportive Care, 2, 33-41. https://doi.org/10.1017/S147 8951504040052

Lazarus, R. S. (1986). Paradygmat stresu i radzenia sobie [Paradigm of stress and coping]. Nowiny Psychologiczne, 3-4, 2-39.

Lazarus, R., \& Folkman, S. (1984). Stress, appraisal and coping. New York: Springer.

Łaguna, M., Trzebiński, J., \& Zięba, M. (2005). Kwestionariusz Nadziei na Sukces KNS. Podręcznik. [The Hope Scale. Manual]. Warszawa: Pracownia Testów Psychologicznych PTP.

Nejat, N., Whitehead, L., \& Crowe, M. (2017). The use of spirituality and religiosity in coping with colorectal cancer. Contemporary Nurse, 53, 48-59. https://doi.org/10.1080/10376178.2016.1276401

Ng, G. C., Mohamed, S., Sulaiman, A. H., \& Zainal, N. Z. (2017). Anxiety and depression in cancer patients: The association with religiosity and religious coping. Journal of Religion and Health, 56, 575-590. https:// doi.org/10.1007/s10943-016-0267-y 
Nipp, R. D., Greer, J. A., El-Jawahri, A., Moran, S. M. Traeger, L., Jacobs, J. M., Jacobsen, J. C., Gallagher, E. R., Park, E. R., Ryan, D. P., Jackson, V. A., Pirl, W. F., \& Temel, J. S. (2017). Coping and prognostic awareness in patients with advanced cancer. Journal of Clinical Oncology, 35, 2551-2557. https://doi.org/10.1200/JCO.2016.71.3404

Ogińska-Bulik, N. (2015). The role of personal resources in the development of trauma in people struggling with cancer. Psychoonkologia, 3, 88-96. https://doi.org/10.5114/pson.2015.57168

Ogińska-Bulik, N. (2011). Rola prężności psychicznej w przystosowaniu się kobiet do choroby nowotworowej [The role of resiliency in adjustment to cancer in women]. Psychoonkologia, 1, 16-24.

Ogińska-Bulik, N., \& Juczyński, Z. (2008). The scale to measure resiliency - SPP-25. Nowiny Psychologiczne, 3, 39-56.

Pérez, J. E., \& Rex Smith, A. (2015). Intrinsic religiousness and well-being among cancer patients: the mediating role of control-related religious coping and self-efficacy for coping with cancer. Journal of Behavioral Medicine, 38, 183-193. https://doi.org/ 10.1007/s10865-014-9593-2

Piórowska, A., Basińska, M. A., Piórowski, K., \& Janicka, M. (2017). The Brief Resilience Coping Scale - polska adaptacja Krótkiej Skali Prężności Zaradczej [Polish adaptation of the Brief Resilience Coping Scale]. Przegląd Pedagogiczny, 1, 178-192.

Piórowska, A., \& Banasik, A. (2015). Nadzieja a elastyczne radzenie sobie ze stresem u policjantów [Coping flexibility and hope in police officers group]. In M. A. Basińska (Ed.), Coping flexibility with stress in health and in disease. Elastyczne radzenie sobie ze stresem $w$ zdrowiu $i$ w chorobie (pp. 175-193). Bydgoszcz: Wydawnictwo UKW.

Preacher, K. J., \& Hayes, A. F. (2004). SPSS and SASS procedures for estimating indirect effects in simple mediation models. Behavior Reserach Methods, Instruments, Computers, 36, 717-731. https://doi. org/10.3758/BF03206553

Reese, J. B., Keefe, F. J., Somers, T. J., \& Abernethy, A. P. (2010). Coping with sexual concerns after cancer: the use of flexible coping. Support Care Cancer, 18, 785-800. https://doi.org/10.1007/ s00520-010-0819-8

Saito, M., \& Kamimura, E. (2011). Coping flexibility and stress responses during a teacher training practicum. Japanese Journal of Health Psychology, 24, 34-44. https://doi.org/10.11560/jahp.24.1_34

Schulz, U., \& Mohamed, N. E. (1982). Turning the tide: Benefit finding after cancer surgery. Social Science \& Medicine, 59, 653-662. https://doi.org/10.1016/j. socscimed.2003.11.019

Snyder, C. R. (2002). Hope theory: Rainbows in the mind. Psychological Inquiry, 13, 249-275. https:// doi.org/10.1207/S15327965PLI1304_01
Sołtys, M., \& Basińska, M. A. (in print). The Spirituality Index of Well-Being by Timothy P. Daaleman and Bruce B. Frey - Polish scale adaptation.

Spendelow, J. S., Eli Joubert, H., Lee, H., \& Fairhurst, B. R. (2018). Coping and adjustment in men with prostate cancer: a systematic review of qualitative studies. Journal of Cancer Survivorship, 12, 155-168. https:// doi.org/10.1007/s11764-017-0654-8

Stępka-Tykwińska, E. (2015). Styles and strategies of coping with stress and flexibility coping among a group of students. In M. A. Basińska (Ed.), Coping flexibility with stress in health and in disease. Elastyczne radzenie sobie ze stresem $w$ zdrowiu $i$ w chorobie (pp. 165-182). Bydgoszcz:Wydawnictwo UKW.

Stępka-Tykwińska, E., Basińska, M. A., Sołtys, M. \& Piórowska, A. (2019). Wybrane cechy osobowości funkcjonariuszy Państwowej Straży Pożarnej jako predyktory elastyczności w radzeniu sobie ze stresem [Selected personality traits as predictors of coping flexibility in a group of officers of the State Fire Service]. Medycyna Pracy, 70, 555-565. https://doi.org/10.13075/mp.5893.00823

Sumpio, C., Jeon, S., Northouse, L. L., \& Knobf, M. T. (2017). Optimism, symptom distress, illness appraisal, and coping in patients with advancedstage cancer diagnoses undergoing chemotherapy treatment. Oncology Nursing Forum, 44, 384-392. https://doi.org/10.1188/17.ONF.384-392

Surtees, P. G., Wainwright, N.W., Luben, R., Khaw, K. T., \& Day, N. E. (2006). Mastery, sense of coherence, and mortality: Evidence of independent associations from the EPIC-Norfolk Prospective Cohort Study. Health Psychology, 25, 102-110. https://doi. org/10.1037/0278-6133.25.1.102

Zelazo, P. D., Müller, U., Frye, D., \& Marcovitch, S. (2003). The development of executive function in early childhood. Monographs of the Society for Research in Child Development, 68, vii-137. https:// doi.org/10.1111/j.0037-976X.2003.00261.x
Personal resources and flexibility in coping in a group of cancer patients 